\title{
Correlation of Profile Lipid Conditions With Oxidative Stress
}

\section{(MDA Malondialdehyde)}

\author{
Septi Nina Maria Ginting*, Melati Silvanni Nasution ${ }^{* *}$, Santi Syafril ${ }^{* *}$, Dharma Lindarto ${ }^{* *}$ \\ * Department of Internal Medicine, Metabolic Endocrinology and Diabetes Division of North Sumatera University, Faculty of Medicine, North \\ Sumatera University, Medan, Indonesia \\ **: Lecturer, Department of Internal Medicine, Faculty of Medicine, North Sumatera University, Medan, Indonesia
}

DOI: 10.29322/IJSRP.11.05.2021.p11324

http://dx.doi.org/10.29322/IJSRP.11.05.2021.p11324

\begin{abstract}
Introduction: Lipid metabolism is a complex enough metabolic reaction in the human body. Lipids have a strong enough appearance with oxidative stress which will form atherogenesis, through the peroxidase reaction. VLDL and LDL are the basic raw materials for peroxidase reactions that will form free radicals and damage blood walls. This study will analyze lipid levels with MDA-Malondialdehyde, as oxidative stress.

Methods: This simple study involved 60 metabolic syndrome patients at Haji Adam Malik General Hospital Medan. The research method used is a cross sectional or cross sectional study. In this study, HDL, LDL, total cholesterol, levels and changes in MDA Malondialdehide levels were examined. In addition, several other metabolic profiles such as blood pressure, abdominal circumference, waist circumference and BMI were also carried out as subjects of the study subjects. Then the analysis was carried out with the Spearman trial.
\end{abstract}

Results: The sample involved in this study was 60 people, consisting of 54 men and 6 women. The median age of the subjects was $28(19-35)$ years, and the mean height was $170.6 \pm 6.7 \mathrm{~cm}$. The results of the Spearman analysis showed that BMI with HDL was found ( $p<0.001)$. In Spearman's observations, MDA also showed the performance of total cholesterol $(\mathrm{p}=0.005)$ and LDL $(\mathrm{p}=$ 0.009).

Conclusion: found lipid levels with oxidative stress MDA malodialdehyde.

\section{INTRODUCTION}

$F^{\prime \prime}$ ree radicals that cause oxidative stress are one of the main causes of atherogenesis. Lipid peroxidase is one of the results of the breakdown of PUFA oxidative reactions. VLDL, LDL is one of the basic ingredients of the peroxidase reaction, and LDL is the most important basic material. Oxidatively, modified LDL (Ox-LDL) causes foam cell growth, which is a major factor in atherosclerosis. Ox-LDL is one of the potential atherogenic materials in individuals, this can be implemented by calculating the quantity of MDA malodialdehyde. 1

Fat peroxidase is a reaction that acts as a mediator for oxidative reactions, once this reaction is initiated, oxidative damage from polyunsaturated lipids is formed. The components that are the most frequent targets are biological membranes. When a reaction occurs in a biological membrane, several compounds such as endotoxins and aldehydes are released, namely malodialdehyde, which consists of three carbon chains, aldehydes with low molecular weight and can be produced by different mechanisms. The lipid profile is the main ingredient in the formation of this reaction. 2 Thus, proper lipid level regulation is necessary to reduce oxidative stress.

\section{METHOD}

The study was conducted at RSUP Haji Adam Malik Medan by collecting patients with metabolic syndrome from both outpatient and inpatient installations. The research method used is cross sectional method. Collection of patients with consecutive sampling method. The number of samples in this study were 60 people.

\subsection{Inclusion Criteria}

In this study, several inclusion criteria were determined, such as: Men and women $\geq 18$ years, clinical diagnosis and laboratory confirmed to have metabolic syndrome. The criteria were assessed by measuring blood pressure, calculating waist and hip circumference, body weight, BMI. After the patient meets the criteria determined as metabolic syndrome, the patient is subjected to laboratory tests for lipid profiles, namely HDL, LDL, and total cholesterol. After that, the examination of MDA levels was also carried out for correlation analysis between the two variables.

\subsection{Exclusion Criteria}

Patients who did not meet all the criteria for metabolic syndrome were excluded from the study. Patients who had a history of myocardial infarction were not included in this study, to avoid bias towards MDA levels.

\subsection{Laboratory examination}

Each patient was subjected to a lipid profile examination. The examination is carried out by first providing education for fasting to the patient. After that, the MDA level was also checked for correlation analysis of the two variables.

\subsection{Statistic analysis}

The characteristics of the study subjects were carried out by looking for the mean value of the gender, age of the patient, and the mean value of the patient's height. The data is presented in the form of a descriptive table. The correlation between BMI and lipid 
profiles, as well as changes in MDA levels and lipid profiles were performed using Spearman's correlation analysis. This analysis was chosen because each normality test of the two variables showed an asymmetric distribution.

\section{RESULTS}

The characteristics of the research sample are presented in tabular form. The characteristics of the study sample were identified by looking at gender, average age and average height.

Table 1. Characteristics of the Sample

\begin{tabular}{ll}
\hline Characteristics & $\mathbf{N = 6 0}$ \\
\hline Gender & \\
Man & 54 \\
Woman & 6 \\
Age $(\text { years })^{\mathrm{b}}$ & $28(19-35)$ \\
Height $(\mathrm{cm})^{\mathrm{a}}$ & $170,6 \pm 6,7$ \\
\hline
\end{tabular}

A normal data distribution; mean $\pm \mathrm{SD}$; paired $\mathrm{t}$ test $\mathrm{b}$ there is abnormal data distribution; median (min-max); the Wilcoxon test

$* \mathrm{p}<0.05 ; * * \mathrm{p}<0.001$

The number of research samples involved in this study is 60 samples. The characteristics of the research sample were based on gender, consisting of 54 men and 6 women. The mean age involved in this study was 28 years (in the range $19-35$ years). The mean height was $170.6 \pm 6.7 \mathrm{~cm}$.

Laboratory parameters are also analyzed and presented in tabular form. The parameter results were assessed by looking for the average value of each parameter using the paired t test for normally distributed data and the Wilcoxon test for abnormally distributed data.

\section{Table 2. Research Subject's Laboratory Parameters}

\begin{tabular}{|c|c|}
\hline Karakteristik & P1 \\
\hline Systolic Pressure $(\mathrm{mmHg})^{\mathrm{a}}$ & $120,3 \pm 9,2$ \\
\hline Diastolic Pressure $(\mathrm{mmHg})^{\mathrm{a}}$ & $81,8 \pm 10,1$ \\
\hline Weigh $(\mathrm{kg})^{\mathrm{b}}$ & $84,5(60-145,5)$ \\
\hline $\operatorname{BMI}\left(\mathrm{kg} / \mathrm{m}^{2}\right)^{\mathrm{b}}$ & $29,0(25,1-42,5)$ \\
\hline Waist circumference $(\mathrm{cm})^{\mathrm{a}}$ & $99,8 \pm 12,7$ \\
\hline Hip circumference $(\mathrm{cm})^{\mathrm{b}}$ & $106,5(88-136)$ \\
\hline Waist/hip ratio ${ }^{\text {b }}$ & $0,98(0,80-1,08)$ \\
\hline Total choleseterol $(\mathrm{mg} / \mathrm{dL})^{\mathrm{a}}$ & $192,6 \pm 35,3$ \\
\hline $\mathrm{HDL}(\mathrm{mg} / \mathrm{dL})^{\mathrm{a}}$ & $50,9 \pm 8,4$ \\
\hline $\mathrm{LDL}(\mathrm{mg} / \mathrm{dL})^{\mathrm{a}}$ & $129,6 \pm 30,5$ \\
\hline HDL/Total Cholesterol ${ }^{\text {a }}$ & $0,28 \pm 0,08$ \\
\hline GDN $(\mathrm{mg} / \mathrm{dL})^{\mathrm{b}}$ & $114(80-139)$ \\
\hline $\mathrm{MDA}^{\mathrm{b}}$ & $4,25(0,97-101,5)$ \\
\hline
\end{tabular}

The laboratory parameters assessed in the present study varied considerably. All parameters that were assessed were to see the average value of each parameter of the subject who had entered the inclusion criteria. The mean systolic blood pressure of the sample was $120.3 \pm 9.2 \mathrm{mmHg}$, for diastolic blood pressure it was
$81.8 \pm 10.1 \mathrm{mmHg}$. The mean value of body weight was 84.5 (60$145.5) \mathrm{kg}$, and for BMI was $29.0(25.1-42.5)(\mathrm{kg} / \mathrm{m} 2)$. For waist circumference $99.8 \pm 12.7 \mathrm{~cm}$, hip circumference 106.5 (88-136) $\mathrm{cm}$. The average value of the ratio of the two, is 0.98 (0.80-1.08). For laboratory tests of metabolic profiles, total cholesterol, HDL, LDL, HDL / total cholesterol ratio, and blood glucose levels were examined. The mean total cholesterol value was $192.6 \pm 35.3$ (mg / dl), the mean HDL value was $50.9 \pm 8.4(\mathrm{mg} / \mathrm{dl})$ for the mean LDL level was $129.6 \pm 30,5$ (mg / dl). The HDL / total cholesterol ratio value was $0.28 \pm 0.08$. The mean blood glucose level was 114 (80-139) mg / dl. Assessment of oxidative stress levels in patients is by examining the patient's MDA levels. The mean value of MDA in all study subjects was 4.25 (0.97-101.5).

Anova test to assess the distribution of data, shows that the data in this study were not normally distributed. The analysis of the two variables was carried out using the Spearman correlation test. The results of these two tests with a significant value of 2 tailed are at $p$ value $<0.05$ or $p<0.01$. The level of strength of the correlation between the two variables can be seen from the $\mathrm{R}$ value in the analysis results. Correlation test of the two variables was carried out on BMI and lipid profile.

Table 3. The Correlation BMI and Lipid Profile

\begin{tabular}{lll}
\hline $\begin{array}{l}\text { Spearman } \\
\text { Correlation }\end{array}$ & IMT & \\
& $\mathrm{R}$ & $\mathrm{P}$ \\
\hline Total Cholesterol & $-0,087$ & 0,508 \\
HDL & $\mathbf{- 0 , 4 4 1}$ & $<\mathbf{0 , 0 0 1 *}$ \\
LDL & 0,025 & 0,850 \\
GDP & 0,190 & 0,147 \\
MDA & $-0,042$ & 0,751 \\
\hline
\end{tabular}

From the Spearman correlation analysis of these two variables it was found that there was a significant correlation between BMI and HDL. The relationship between these two variables is inversely proportional to the results of the analysis of the value of $\mathrm{R}-0.441$. The results of this analysis mean that an increase in BMI will reduce the value of HDL, and this relationship is quite strong with an $\mathrm{R}$ value of -0.441 . For the other lipid profiles, no significant association was found.

Spearman correlation analysis was also performed on variables between lipid profiles and MDA. The analysis results are shown in table 4.

Table 4 The Correlation Lipid Profile and MDA

\begin{tabular}{lll}
\hline Spearman & MDA & \\
Correlation & & $\mathrm{P}$ \\
\hline Total Cholesterol & $\mathrm{R}, 356$ & $\mathbf{0 , 0 0 5 *}$ \\
HDL & $-0,057$ & 0,667 \\
LDL & $\mathbf{0 , 3 3 6}$ & $\mathbf{0 , 0 0 9 *}$ \\
GDP & 0,063 & 0,633 \\
\hline
\end{tabular}

In the Spearman correlation analysis, it was found that there was a significant relationship between total cholesterol and changes in MDA ( $\mathrm{p}$ value <0.05). The two variables show a positive relationship, meaning that an increase in total cholesterol 
will increase changes in MDA. The correlation between the two relationships has a strong enough relationship with the value of $\mathrm{R}$ $=0.356$. Similar results were found for the LDL variable and MDA changes ( $\mathrm{p}$ value $<0.05$ ). The two variables have a positive relationship, meaning that an increase in LDL will increase changes in MDA. The correlation between the two variables is quite strong with a value of $\mathrm{R}=0.336$.

\section{DISCUSSION}

This study aims to determine the relationship between lipid profiles and oxidative stress. Lipid abnormalities significantly contribute to the increase in cardiovascular disease and morbidity from diabetes. Men and women appear to be at equal risk of cardiovascular disease because of the effects of risk factors such as hypertension, elevated plasma LDL and low plasma HDL levels. However, it should be noted that this increase is quite controlled in women who have the hormone estrogen as a factor to increase HDL and reduce LDL levels. ${ }^{7}$

Metabolic syndrome criteria were established according to the International Diabetes Federation consensus. A person who has metabolic syndrome must have the following criteria, namely: patients with central obesity who are defined according to the criteria of each ethnicity. For Asia-India it was determined that a person with central obsession if the waist circumference for men was $\geq 90 \mathrm{~cm}$ and for women $\geq 80 \mathrm{~cm}$. Other criteria that are also considered for metabolic syndrome are an increase in triglycerides $\geq 150 \mathrm{mg} / \mathrm{dl}(1.7 \mathrm{mmol} / \mathrm{L})$, a decrease in HDL cholesterol $<40$ $\mathrm{mg} / \mathrm{dl}$ (1.03 mmol / L) for men and <50 mg / dl for men. woman. Increased blood pressure is also a consensus for metabolic syndrome, systolic blood pressure $\geq 130 \mathrm{mmHg}$ or diastolic blood pressure $\geq 90 \mathrm{mmHg}$. The increase in fasting blood glucose levels on this criterion was set at $\geq 100 \mathrm{mg} / \mathrm{dl}(5.6 \mathrm{mmol} / \mathrm{L})$. In this study, all samples have criteria in accordance with the consensus of the IDF.

Lipid and body fat profiles have been shown to be important predictors of metabolic disorders, including dyslipidemia, hypertension, diabetes, cardiovascular disease and hyperinsulinemia.3 Several epidemiological studies have shown that BMI is a significant predictor of cardiovascular disease and diabetes mellitus. The relationship between lipid profiles was reported epidemiologically with respect to age, intra-abdominal adipose levels, obesity and BMI. Several other epidemiological studies have shown a direct correlation between an increase in BMI and an increase in total cholesterol, LDL (low density lipoprotein), and triglycerides and an inverse relationship with HDL. A study conducted by Bansal Prenal, et al. On 136 patients with type 2 diabetes mellitus performed BMI analysis with profile levels in all samples. This study shows a positive correlation between BMI and levels of LDL, as well as a negative correlation with HDL. This study has the same results as this study, where the Spearman correlation results found that the correlation test found a significant relationship between HDL and BMI, and the R value of the analysis results was -0.441 . These results indicate that an increase in BMI will reduce HDL levels. ${ }^{4}$

Basically, genetics has a significant influence on the work of HDL. The HDL system works by transporting cholesterol that is on the walls of blood vessels by first binding to cell surface receptors. Genetic considerations have also been found reported in several studies of the absence of an apolipoprotein A-I mutation, a major component of HDL. This situation is genetically seen in the presence of defects or damage from HDL efflux. In large population studies, low dyslipidemia HDL-C levels are the biggest factor in obesity. And vice versa obesity is a determinant factor for decreasing HDL-C levels. $6,7,8,9$

Free radicals will cause cell damage. This condition is caused by damage to cells that have accumulated over the years. One of the known causes of free radicals forms an oxidative stress in stress. Free radicals are highly reactive and will cause bad changes in several components of living cells, such as proteins, lipids, carbohydrates and nucleic acids. Free radicals will attack the fat components of the cell wall and will cause a peroxidase reaction, producing toxic substances for cells such as malondialdehyde (MDA). Malondialdehyde (MDA) is one of the products produced from lipid peroxidase reactions which is used as a marker of oxidative stress. In conditions of high enough oxidative stress, serum MDA will increase significantly. ${ }^{10}$

In this study, an analysis was carried out between the lipid profile and changes in MDA levels. The correlation between total cholesterol levels and changes in MDA levels was found to be significant ( $p$ value $<0.05$ ) and the relationship between these two variables was strongly positive, with an $\mathrm{R}$ value of 0.356 . With the understanding that an increase in total cholesterol levels will increase MDA levels. In addition, this study also found that changes in MDA levels had a significant correlation with LDL. This relationship is significant with $p$ value $<0.05$. The correlation of these two variables has a positive $\mathrm{R}$ value of 0.336 . This also suggests that an increase in total cholesterol levels will increase changes in MDA levels.

Malondialdehyde (MDA) is a natural product produced in all mammalian cells as a product of lipid peroxidase, which is produced as a product of fatty acid peroxidase and arachidonic acid metabolism. These compounds are known to have a strong correlation with oxidative stress which will have many effects on smooth muscle contraction of the upper airways, induction of upper airway hyperresponsiveness, mucus hypersecretion and vascular exudation or plaque formation. In a study conducted by Naama Lamia, Saudi Arabia, it was found that there was an increase in MDA levels with several lipid profiles such as total cholesterol and LDL-C. ${ }^{11}$

\section{CONCLUSION}

Lipid profile is a metabolic profile that has a strong influence on the peroxidase reaction for free radicals. Based on this study, it can be concluded based on the analysis that there was a significant correlation between lipid levels and changes in MDA.

\section{REFERENCES}

[1] Rao Venkata, Kiran Ravi, et al. Evaluation of correlation between oxidative stress and abnormal lipid profile in coronary artery disease. JCDR. 2019; 2(1): 57-60p

[2] Grotto Denise, Santa Lucas, Valenitine Juliana, et al. Importance of the Lipid Perdoxidation Biomarkers And Methodological Aspects For Malondialdehide Quanitification. Quim Nova. 2009; 32(1):169-174p

[3] Singh Hardev, Koley Shyamal, Singh Karanjit. A Study of Correlation between Lipid Profile and Body MassIndex (BMI) in Patients with Diabetes Mellitus. Kamla Raj. 2008; 24(3):227-229p 
[4] Bansal Prerna, Prasad Hari. Correlation Between Body Mass Index and Lipid Profile in a Diabetic Population of Central Nepal. Journal of College of Medical Sciences-Nepal. 2018; 14(4): 184-188p

[5] Health and Services Oregon and Southwest Washington. Lipid profile (cholesterol and triglycerides). [Internet]. 2018 [cited 2018Dec11]. Available from: https://oregon.providence.org/our-services/1/lipid-profilecholesterol-and-triglycerides/

[6] Lautsch D, Ferriers J, Horack M, et al. Do blood lipids correlate to Body Mass Index?. Dysis. 2019; 3(9): 1p

[7] N.B. Rizvi and S.A. Nagra,Minerals and Lipids Profilesin Cardiovascular Disorders in South Asia, CSpringer-Verlag Berlin Heidelberg 2014

[8] Rashid Shirya, Genest Jacques. Effect of Obesity on High-density LipoproteinMetabolism. Obesity. 2007; 15(12): 2875-2884p

[9] Bora Kaustubh, Saika Mauchumi, Borah Probodh, et al. Association of Decreased High-Density Lipoprotein Cholesterol (HDL-C) With Obesity and Risk Estimates for Decreased HDL-C Attributable to Obesity: Preliminary Findings From a Hospital-Based Study in a City From Northeast India. Journal of Primary Care \& Community Health2017, Vol. 8(1) 26 -30p

[10] Ngestiningshih Dwi, Andayani Rejeki, Batubara Lusiana. The Effect of Superoxide Dismutase (SOD) Supplementation Towards Plasma Levels of Malondialdehyde (MDA), Total Cholesterol and LDL Cholesterol in the Elderly. J. Biomed. 2019; 5(2): 29-32p

[11] Naama Lamia. Serum Malondialdehyde, Total Cholesterol, High Density Lipoprotein and Vitamin C in Welder Workers. Medical Journal of Babylon.
2009; 6(2): 1-7p The International Federation of Diabetes. Metabolic Syndrome. 2019; p1

\section{AUTHORS}

First Author - Septi Nina Maria Ginting, Department of Internal Medicine, Metabolic Endocrinology and Diabetes Division of North Sumatera University, Faculty of Medicine, North Sumatera University, Medan, Indonesia

Second Author - Melati Silvanni Nasution, Department of Internal Medicine, Metabolic Endocrinology and Diabetes Division of North Sumatera University, Faculty of Medicine, North Sumatera University, Medan, Indonesia Third Author - Santi Syafril, Lecturer, Department of Internal Medicine, Faculty of Medicine, North Sumatera University, Medan, Indonesia

Fourth Author - Dharma Lindarto, Lecturer, Department of Internal Medicine, Faculty of Medicine, North Sumatera University, Medan, Indonesia 